\section{Estado e}

\section{oligarquias}

na Primeira

República:

um balanço

das principais

tendências

historiográficas

Marieta de Moraes Ferreira[1]

Surama Conde Sá Pinto[2]

\section{Resumo}

Este artigo tem como objetivo discutir a literatura produzida entre os anos 1950 e 2000 sobre Estado e oligarquias na Primeira República brasileira (1889-1930). A proposta justifica-se em função da existência de um conjunto significativo de textos produzidos por especialistas de diferentes áreas sobre o tema. Como forma de contribuir para o avanço desse debate, pretendemos realizar um balanço mapeando as principais tendências observadas e indicando o que ainda precisa ser objeto de maior investigação por parte dos pesquisadores. Adotamos três critérios na triagem de trabalhos discutidos: a inclusão no universo de análise de livros e artigos produzidos na área das ciências sociais com enfoque histórico, considerados clássicos, que permanecem como referências importantes; uma bibliografia mais atual, ou seja, livros e artigos que retomam essas interpretações para, a partir delas, renovar determinadas chaves de leitura; e a não inclusão de teses (salvo casos excepcionais) e textos de época.

Palavras-chave: Estado; oligarquias; Primeira República.

State and oligarchies in the First Republic: an assessment of key historiographical trends

\begin{abstract}
The aim of this article is to discuss the literature on State and oligarchies in Brazilian's First Republic (1889-1930). The proposal is justified by the existence of a significant set of texts produced by specialists from different areas about this subject. As a way to contribute to the advancement of this debate we intend to accomplish a balance mapping the main trends observed and indicate what still needs to be the object of further researchs. We adopted three criteria in the screening of works discussed: the inclusion in the universe of analysis of books and articles produced in the social sciences areas with an explicit historical approach considered classics that remains as important references until today; a more recent bibliography that takes up these consecrated interpretations to renew certains explanatories models; and the non inclusion of theses (only in exceptional cases) and texts produced during the Brazilian's First Republic.
\end{abstract}

Keywords: Historiographie; State; oligarchies; First Republic. 


\section{Introdução}

Escrever um artigo discutindo a literatura sobre Estado e oligarquias no Brasil na Primeira República (1889-1930), proposta apresentada neste artigo, não é um empreendimento fácil. $\mathrm{Na}$ execução de tarefas dessa natureza sempre se corre o risco de deixar de fora algum autor ou contribuição importante. O desafio, por outro lado, é justificável em função basicamente do fato de já dispormos de um conjunto significativo de textos produzidos por especialistas de diferentes áreas e que trazem mudanças significativas nas interpretações sobre o tema. Assim, uma forma de contribuir para o avanço desse debate é realizar balanços como este, que se propõe mapear as principais tendências observadas e indicar o que ainda precisa ser objeto de maior investigação por parte dos pesquisadores. ${ }^{1}$

Como todos os textos que discutem produção bibliográfica, na elaboração deste artigo foram definidos alguns critérios. O primeiro deles foi a opção de incluir no universo de análise livros e artigos produzidos na área das ciências sociais com um explícito enfoque histórico que abordam direta ou indiretamente a relação entre Estado e oligarquias na Primeira República. Assim, foram selecionados, de um lado, textos considerados clássicos pelas contribuições e debates que desencadearam quando produzidos e que, de certa forma, permanecem como referências importantes até hoje, e, de outro, uma bibliografia mais atual, ou seja, livros e artigos que retomam essas interpretações consagradas para, a partir delas, renovar determinadas chaves de leitura.

Outra preocupação tomada foi a de examinar trabalhos publicados, não incluindo - a não ser excepcionalmente - teses acadêmicas ainda não editadas.

Foi feita também a opção pela não inclusão de textos de época produzidos no momento da mudança de regime e contemporâneos à Primeira República. Ficam, assim, de fora dessa análise trabalhos como o de Vicente Licínio Cardoso (1924), À margem da história da República, que consiste em uma reflexão crítica sobre o regime inaugurado em 1889, elaborada com a colaboração de um grupo de intelectuais da época, e o de Silvio Romero (1910), autor de Provocações e debates: contribuições para o estudo do Brasil social, obra na qual propõe uma tipologia para classificar as oligarquias observadas no país. ${ }^{2}$ Muitos outros livros produzidos no mesmo período poderiam ser aqui citados. O exame dessa produção, no entanto, foge aos objetivos deste artigo, que são mapear o estado da arte das discussões sobre Estado e oligarquias na Primeira República, relacionando o contexto político e intelectual em que boa parte dessa produção emergiu, e destacar o que de novo vem sendo acrescentado a esse debate.

${ }^{1}$ Aqui são retomadas muitas das proposições defendidas por Marieta de Moraes Ferreira e Angela de Castro Gomes no artigo bibliográfico sobre a Primeira República, publicado em 1989, e incorporadas novas contribuições produzidas posteriormente à sua publicação (Gomes e Ferreira, 1989).

2 O texto de Vicente Licínio, espelhando o clima de reflexão crítica inaugurado com o centenário da Independência, foi publicado em 1924 e só veio a ser reeditado pela Universidade de Brasília (UnB) na coleção Biblioteca do Pensamento Político Republicano em 1981. 
Vale ainda destacar que temáticas relacionadas com cultura, movimentos sociais e operário não serão objeto de discussão, pois incluí-las ampliaria muito o escopo de nossa análise e não é nossa proposta aqui realizar um balanço historiográfico da Primeira República, mas apenas discutir a bibliografia mais específica sobre as relações entre Estado e oligarquias no período.

Finalmente, optamos por não partir de nenhuma definição a priori de Estado ou oligarquias, respeitando os diferentes sentidos conferidos pelos autores cujas obras são referenciadas.

No exercício do balanço dessa produção aqui proposto, não temos ilusões quanto às inevitáveis falhas e omissões em relação às quais somos inteiramente responsáveis. O risco é desagradável, mas de certa forma necessário, conforme já assinalado, para o avanço do debate.

\section{Mapeando a historiografia}

Existe um conjunto de trabalhos que, pelo pioneirismo de suas contribuições e influência exercida, figuram em posição de destaque na produção historiográfica relativa às bases de funcionamento do sistema político brasileiro na Primeira República. São os casos das obras de Victor Nunes Leal (1975), Nelson Werneck Sodré (1943, 1962), Celso Furtado (1959, 1975) e Leôncio Basbaum (1976), para citar algumas.

Em meio a esses esforços de reflexão, ganha forma determinada linha de interpretação sobre o sistema político brasileiro na Primeira República que, a despeito de diferenças específicas, defende a existência de uma contradição fundamental entre os setores agrário-exportador e urbano-industrial. De acordo com essa perspectiva, no embate entre esses dois setores, as classes médias exerceriam papel de vanguarda das reivindicações burguesas.

Nesse modelo de análise, veiculado na obra de Werneck Sodré (1962) e de autores como Hélio Jaguaribe (1962), a Primeira República é interpretada como um período marcado por um sistema de dominação baseado no latifúndio, cuja dinâmica comportaria três fases: a da implantação, caracterizada pelo predomínio do poder da classe média pela atuação dos militares; a da consolidação, controlada pelas oligarquias latifundiárias; e a do declínio, marcada tanto pela expansão da burguesia industrial e da classe média quanto pela disputa desses setores pelo controle do poder. Assim, o movimento que pôs fim ao modelo político vigente na Primeira República, conhecido como Revolução de 1930, representaria o conflito entre os setores urbano-industrial e agrário-exportador, traduzido na luta entre a burguesia e o latifúndio.

É importante ressaltar que essa interpretação guarda relação com um modelo mais amplo de interpretação da realidade brasileira, defendido pelo Partido Comunista Brasileiro (PCB) e, em certa medida, pelo movimento nacionalista, nos anos 1950, cuja tese central está baseada 
no pressuposto da existência de dois setores socioeconômicos básicos: o pré-capitalista e o urbano-capitalista. O primeiro, localizado no campo, teria como expressão máxima o latifúndio, nele predominando as relações de tipo semifeudal. Já o segundo, situado nos centros urbanos, teria dado origem a uma burguesia industrial e às classes médias urbanas. Como desdobramento, nesse esquema, os conflitos de classe no país são vistos como resultado do antagonismo entre o latifúndio (aliado ao imperialismo) e as forças nacionais, formadas pelos segmentos da burguesia nacional, pela pequena burguesia e pelas classes populares.

Com o golpe civil-militar de 1964, que interrompe a experiência liberal democrática inaugurada no Brasil a partir de 1945, a derrota das esquerdas e do PCB emergiram novas interpretações sobre a realidade brasileira. É o caso, para citar um exemplo, do livro de Caio Prado Jr., A revolução brasileira, no qual são feitas críticas às atividades políticas das esquerdas, em particular ao PCB, e apontados equívocos das teses dominantes (Prado Jr., 1966, 1970).

Os debates ensejados pelo livro de Prado Jr. produziram frutos. Um deles é o artigo de Paula Beiguelman a propósito de uma interpretação da história da República, no qual é feita uma revisão das interpretações sobre a Primeira República (Beiguelman, 1967, 1968). Analisando criticamente as teses de Werneck Sodré, a autora questiona a existência de contradições fundamentais entre setor agrário e setor urbano-industrial no Brasil. Beiguelman utiliza como referência a própria periodização proposta por Sodré para mostrar que a primeira fase republicana não representou uma dominância dos setores urbano-industriais e que a política econômica implementada no período não foi uma resposta direta aos interesses urbanos. De acordo com ela, o antagonismo do setor urbano com o setor exportador era apenas superficial, pela própria natureza e configuração do primeiro. No que diz respeito à segunda fase, marcada, segundo Sodré, pelo predomínio do latifúndio sobre as demais classes, a autora destaca a simplificação da análise. Da mesma forma, Beiguelman questiona a ideia de que as agitações da década de 1920 e a Revolução de 1930 representariam uma luta entre a burguesia e o latifúndio. Segundo a autora, a chave para a compreensão do episódio deve ser deslocada para a crise institucional, aberta com a transformação das bases estruturais que haviam dado sentido ao sistema político-administrativo descentralizado vigente na Primeira República, e para a alteração da posição do setor agrário-exportador dentro da economia nacional, com a criação de um núcleo econômico voltado para o mercado interno, passível de transformar-se em componente dinâmico. Concluindo sua argumentação, Beiguelman defende que a crise do setor cafeeiro, a partir de 1929, viria contribuir para evidenciar a necessidade de remediar o progressivo empobrecimento de outras áreas do país. Provocando eco no meio acadêmico, algumas dessas hipóteses seriam aprofundadas por Eduardo Kugelmas no artigo intitulado "A Primeira República no período de 1891 a 1909" (Kugelmas, 1968).

Maria do Carmo Campelo de Sousa é autora de outro texto fundamental no qual são tecidas críticas às teses dominantes nos anos 1950 e 1960 (Sousa, 1972). Priorizando a análise 
do processo político-partidário brasileiro entre 1889-1930, Campelo de Sousa defende que o desenvolvimento industrial não só não criou um antagonismo com o antigo setor exportador, como havia uma complementaridade de interesses das duas esferas econômicas. Para sustentar seu argumento, a autora analisa as conjunturas classicamente consideradas como de expansão dos setores urbanos (governos Deodoro, Floriano Peixoto, Hermes da Fonseca e a década de 1920) e demonstra que esses períodos não representaram perda para os interesses das oligarquias. Seu trabalho discute ainda a caracterização da organização política republicana e traça um quadro dos diferentes governos, dando ênfase à montagem do pacto oligárquico e da chamada política dos governadores.

A mesma linha de interpretação está presente no artigo escrito no mesmo período por Boris Fausto, intitulado “A Revolução de 30", e no livro também de sua autoria A Revolução de 30: historiografia e história, publicado em $1970 .{ }^{3}$ Neste último, originalmente apresentado como tese de doutorado, por meio de uma análise historiográfica, são aprofundadas as críticas às concepções que interpretam os conflitos da Primeira República como produto do antagonismo entre o setor agrário-exportador e setores urbano-industriais, nas quais a Revolução de 1930 é compreendida como o resultado final desse embate. Fausto chama a atenção para a dificuldade de se definir classe média do período, dada a heterogeneidade de sua composição, e para os equívocos de pensar que essa classe teria desempenhado um papel de vanguarda das reivindicações burguesas, uma vez que seu horizonte ideológico, não raro, identificava-se com os das oligarquias. Quanto ao suposto antagonismo entre as frações da classe dominante (burguesia agroexportadora e urbano-industrial), examinando o perfil da indústria brasileira na Primeira República, defende que, apesar de interesses diferentes, o que predominava era uma relação caracterizada pela subordinação e complementaridade.

Questionando a ideia de que o movimento de 1930 no Brasil seria uma revolução, já que não foram processadas mudanças estruturais na sociedade, o autor propõe, como interpretação alternativa, caracterizá-lo como resultado de conflitos intraoligárquicos, fortalecidos por movimentos militares dissidentes, que tinham como objetivo golpear a hegemonia da burguesia cafeeira. Ainda segundo o autor, em virtude da incapacidade das demais frações de classe para assumir o poder de maneira exclusiva, e com o colapso político da burguesia do café, abriu-se um vazio de poder. A resposta para essa situação foi o que chamou, a exemplo de Francisco Weffort (1978), de Estado de compromisso, entendido como um Estado que, embora aberto à demanda de diferentes setores da sociedade, não se submeteu a nenhuma classe ou fração de classe. Vale destacar que o conceito de bonapartismo de Marx orientou essa interpretação.

${ }^{3}$ Não poderíamos deixar de fazer referência aqui também aos diversos trabalhos de Edgar Carone que representam uma referência importante para o conhecimento da Primeira República, pelas análises, informações e corpos documentais neles disponibilizados. Ver Carone $(1969,1971,1972)$ 
Aprofundando trabalhos anteriores, em 1972, Boris Fausto publicou Pequenos ensaios de história da República, no qual são analisadas as linhas gerais da formação social brasileira e as bases do sistema político na Primeira República (Fausto, 1972). Entre as ideias defendidas pelo autor está a de que a concentração das atividades econômicas em áreas geográficas definidas propiciou a formação, no país, de uma estrutura regional de classes. As oposições entre os diferentes grupos regionais no interior da classe dominante teriam, assim, em sua perspectiva, mais importância do que as divisões setoriais (burguesia agrária, comercial, industrial).

Com essa proposição, Fausto não só aprofunda as críticas às interpretações dualistas (contradições entre oligarquias agrárias e setores urbano-industriais), como oferece novos subsídios para melhor explicitar o papel da oligarquia cafeeira no jogo político do período. Em suas palavras: "[...] sua capacidade de articulação permitiu que ela fosse mais que beneficiária da ação do Estado e que forjasse as instituições estatais e as transformasse no instrumento do seu interesse" (Fausto, 1972, p. 5). Explicitava-se, assim, um dos modelos mais importantes para entender a natureza dos conflitos políticos e o papel do Estado na Primeira República: a tese da representação de interesses, segundo a qual, grosso modo, o Estado seria uma espécie de comitê executivo da classe dominante, ou seja, da burguesia cafeeira.

Nos anos 1970, também sob a coordenação desse autor, foram publicados dois volumes da coleção História geral da civilização brasileira, dedicados à Primeira República: Estrutura de poder e economia (v. 8) e Sociedade e instituições (v. 9). Os livros incorporaram a colaboração de autores com diferentes orientações teórico-metodológicas, fornecendo um painel dos principais temas do primeiro período republicano. ${ }^{4}$

Também no campo dos estudos sobre as oligarquias, é importante mencionar a produção dos brasilianistas Joseph Love (1975, 1982), John Wirth (1975) e Robert Levine (1975), cujas análises contribuíram significativamente para a compreensão do funcionamento do federalismo brasileiro na Primeira República. Esses autores desenvolveram um projeto comparativo sobre as elites regionais, priorizando os casos de São Paulo, Minas Gerais e Pernambuco, oferecendo um painel dinâmico da economia, do povo, da sociedade e da cultura brasileira entre 1889 e 1937, recorte temporal por eles adotado. Essas obras serviram de estímulo para estudiosos nacionais e estrangeiros produzirem análises da mesma natureza, privilegiando outras unidades da Federação, que serão comentados mais adiante. Love já havia anteriormente publicado um estudo sobre o Rio Grande do Sul, e Eul Soo Pang publicaria, em 1979, um estudo sobre a oligarquia baiana (Pang, 1979).

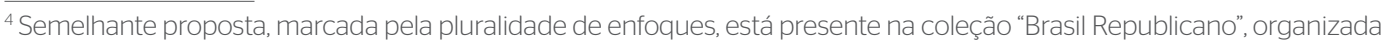
por Jorge Ferreira e Lucília Delgado, publicada em inícios dos anos 2000, na qual são veiculadas, no volume 1, contribuições de diversos pesquisadores e são revistos tradicionais enunciados sobre a Primeira República nos campos da política, da economia, da sociedade e da cultura (Ferreira e Delgado, 2003). 
Conforme visto até aqui, no balanço da produção bibliográfica das décadas de 1960 e 1970, a despeito das especificidades, é possível perceber que foi privilegiada a ideia de que a hegemonia política da oligarquia paulista, em aliança com a mineira, sustentava-se na preeminência da economia exportadora cafeeira. Como desdobramento dessa leitura, o arranjo político oligárquico entre São Paulo e Minas, conhecido como política do café com leite, ditaria de forma nítida a orientação do governo federal.

Os elementos que estruturam essa perspectiva de análise, fundamentada no predomínio dos interesses ligados ao café, ${ }^{5}$ o que explicaria a ascendência dos estados de São Paulo e Minas Gerais no conjunto da Federação brasileira da Primeira República, podem ser encontrados no texto clássico do economista Celso Furtado (1959), Formação econômica do Brasil.

Para esse autor, o Poder Executivo não só teria atuado no período no sentido de sustentar os planos de valorização do café, como a política financeira praticada pelo Estado brasileiro esteve voltada para o beneficiamento desse setor. Havia, assim, nessa perspectiva de análise, uma quase total subordinação da política econômica do governo federal aos desígnios do setor cafeeiro. Tal leitura levou Celso Furtado a elaborar o conceito de socialização de perdas, por entender que, por mecanismos de depreciação cambial, foram socializados os prejuízos dos cafeicultores, provenientes do declínio dos preços do café no mercado externo, em várias conjunturas.

Com o objetivo de testar essas interpretações, que privilegiam a oligarquia cafeeira como um ator fundamental e quase exclusivo na condução da política do período, surgiu um significativo número de trabalhos. Em meio a esse movimento, contribuições interessantes começaram a ser construídas por economistas que, não raro, em suas teses de doutorado, dedicaram-se ao estudo da política econômica e financeira da Primeira República.

Ainda nos anos 1970, os trabalhos de Peláez (1971) e Vilela e Suzigan (1973) apresentaram a ideia de que a condução da política econômica foi predominante e constantemente influenciada pela utilização de princípios ortodoxos de política monetária fiscal e cambial, não sendo, portanto, um reflexo direto dos interesses cafeeiros.

Esses trabalhos, embora não tenham apresentado uma explicação do porquê da utilização das doutrinas ortodoxas no período, abriram caminho para um questionamento das teses que interpretavam a orientação da política econômica adotada pelo Estado brasileiro na Primeira República como decorrência imediata dos interesses do café.

A revisão aberta por esses autores ganharia reforço com a publicação dos trabalhos do também economista Winston Fritsch, "Aspectos da política econômica no Brasil: 19061914”, e “Apogeu e crise na Primeira República: 1900-1930” (Fritsch, 1980a, 1983, 1985, 1989).

$\overline{5}$ Os dois estados, São Paulo e Minas Gerais, eram os maiores produtores de café do Brasil no período. Após superar o estado do Rio de Janeiro, ocupando o segundo lugar no ranking nacional, Minas Gerais passou a ser responsável por 20\% da produção do país. Ver Cano (1985, p. 291-306). 
Neles, Fritsch questiona o pressuposto de que a política econômica do governo federal teria consistentemente favorecido os interesses corporativos ligados ao café. Embora não negue a posição hegemônica desses grupos em relação ao Estado brasileiro, o autor relativiza as afirmações de que o governo federal sempre se curvou às pressões da cafeicultura, apoiando programas de valorização do café e favorecendo a depreciação cambial. Estruturando suas análises em uma ampla pesquisa documental, defende que o governo federal ou negou seu apoio aos planos de valorização, como em 1906 e 1929, ou apenas interveio de maneira esporádica e limitada.

A explicação para essa forma de procedimento está relacionada, segundo Fritsch, com as pressões contrárias provenientes de outros grupos regionais, bem como com a oposição dos banqueiros internacionais. Assim, nos momentos em que auxílios mais efetivos foram concedidos à cafeicultura, essas iniciativas, longe de significar a intenção de dar um tratamento preferencial ao setor cafeeiro, visavam a evitar que um declínio demasiado dos preços do café trouxesse graves consequências para o desempenho da economia como um todo.

Esse debate teve desdobramentos. Novos estudos foram produzidos, como os trabalhos de Barroso Franco $(1983,1989)$ e Steven Topik $(1988,1989)$, sendo privilegiada como conjuntura de análise, principalmente, a fase de transição do Império para a República.

A principal contribuição de Barroso Franco diz respeito à discussão desenvolvida sobre as origens das motivações econômicas para a adoção de políticas ortodoxas em várias conjunturas. Conforme argumenta, o enraizamento de uma orientação econômica ortodoxa esteve relacionado com a generalização da crença, nascida nos primórdios da república, de que a desvalorização cambial era fruto do excessivo crescimento das emissões de moeda. Dessa forma, as reformas de 1898-1900, ao permitirem a expansão monetária, teriam cumprido o vaticínio metalista: provocaram irremediavelmente a baixa do câmbio.

A aceitação desse diagnóstico teve como consequências, na época, o bloqueio de quaisquer possibilidades de avanço posterior das reformas monetárias e a ascensão da ortodoxia financeira. Segundo Barroso Franco, a afirmação dessa perspectiva contribuiu grandemente para que fossem adotados pela elite política procedimentos econômicos ortodoxos, muitas vezes contrários e prejudiciais aos interesses específicos da oligarquia cafeeira.

No campo das análises dos historiadores e cientistas políticos, essa tendência para relativizar o papel e o peso de São Paulo e da oligarquia cafeeira foi ampliada no decorrer dos anos 1980 e 1990. Boris Fausto chegou inclusive a publicar um artigo no qual, incorporando as contribuições dos economistas, relativiza muitas das interpretações por ele defendidas, nos anos 1970, sobre o perfil do Estado e o alcance dos interesses agroexportadores no período (Fausto, 1990). Essa orientação também é sustentada por Renato Perissinoto em estudo que analisa a política monetária e cambial no período do encilhamento, no qual o autor questiona a clássica tese de Celso Furtado (Perissinoto, 1995, p. 55). 
O surgimento de novos trabalhos centrados na análise da atuação das demais oligarquias regionais e/ou na revisão do papel das oligarquias consideradas dominantes - São Paulo e Minas - contribuiu para permitir um melhor desenho do sistema político da Primeira República e apontar as complexidades do pacto oligárquico.

São contribuições importantes e que atendem aos dois últimos objetivos apontados os trabalhos de José Murilo de Carvalho $(1987,1990)$ e de Renato Lessa $(1987,2001)$. Em Os bestializados, Carvalho discute o processo de construção da cidadania republicana, destacando o divórcio que a república promoveu entre a sociedade civil e a sociedade política. ${ }^{6}$ Analisando os diferentes modelos de cidadania em disputa no período de implantação do novo regime (o positivista, o radical e o liberal), o autor mostra que o modelo vitorioso representou a exclusão da participação política formal de grande parte da sociedade brasileira à época, uma vez que foram fixados os critérios de nacionalidade, idade e alfabetização para qualificação dos eleitores (Carvalho, 1897, p. 65). Seu trabalho proporciona ricos elementos para a compreensão tanto das práticas oligárquicas que visavam a impedir a extensão da cidadania a contingentes mais amplos da população brasileira quanto do exercício de cidadania informal observado no período.

Já o trabalho de Renato Lessa, A invenção republicana, investiga a implantação da ordem política republicana, concentrando sua atenção na análise da "infância" da república brasileira e do papel da política dos governadores como fator de estabilidade da ordem oligárquica. Para o autor, o pacto criado procurou solucionar três problemas que a Constituição de 1891 não havia resolvido: o das relações entre os Poderes Executivo e Legislativo, o das relações entre governo central e governos regionais e a questão do recrutamento político. Com a fórmula adotada, o Executivo federal passou a sustentar os grupos dominantes nos estados, enquanto estes, em troca, apoiavam a política do presidente da república, votando no Congresso com o governo. Esse acordo entre a União e os estados, segundo Lessa, diminuiu as hostilidades existentes entre Executivo e Legislativo pelo controle da escolha dos deputados, ao mesmo tempo que confinou os conflitos intraoligárquicos à esfera regional. É importante ressaltar que a tese de Lessa é a de que, a partir da política dos governadores, houve um congelamento dos conflitos políticos, restringindo a alternância dos grupos ao poder (Lessa, 1987, p. 109). ${ }^{7}$ Fundamentada em fontes secundárias, essa interpretação manteve, em grande medida, a tese de Fernando Henrique Cardoso de que o pacto Campos Sales seria o equivalente funcional do Poder Moderador (Cardoso, 1975).

${ }^{6} \mathrm{O}$ objetivo de Carvalho, no livro, é analisar os relacionamentos entre cidadão e Estado, cidadão e sistema político e cidadão e a própria atividade política no Brasil no novo regime. Nele, o autor questiona a visão maniqueísta segundo a qual o Estado é visto como vilão e a sociedade como vítima inocente. Carvalho parte do pressuposto de que a relação cidadão e Estado é uma via de mão dupla, pois todo sistema político, para sobreviver, precisa desenvolver uma base de legitimidade.

${ }^{7}$ Vale destacar que, em 2014, Christian Lynch lançou Da monarquia à oligarquia, trabalho no qual reproduz, em grande medida, as linhas básicas do esquema interpretativo de Lessa. Ver: Lynch (2014) 


\section{Alianças, dominação e participação dos estados na Federação brasileira em questão}

A nova tendência, observada a partir dos anos 1980, marcada pela revisão do papel das oligarquias consideradas dominantes (a paulista e a mineira) e pelo resgate da experiência das demais oligarquias regionais, no entanto, aparece de forma mais pronunciada em estudos elaborados em Programas de Pós-graduação em história, salvo algumas exceções, a partir dos anos 1990. São os casos dos trabalhos de Kugelmas (1986), Martins Filho (1987), Ferreira (1994), Enders (1993), Freire (2000), Viscardi (2001), Pinto (2002, 2011), Fanaia (2010), Gunter (2011), Sarmento (2011), Negro e Brito (2013) e Quintão (2016), produzidos no contexto da Nova República.

Assim, o papel desempenhado por São Paulo recebeu a atenção de Eduardo Kugelmas (1986), que, em sua tese de doutorado, relativizou a ideia da hegemonia paulista, chamando a atenção para conflitos setoriais e regionais, e defendeu uma revisão profunda da ideia de existência de um controle simples e direto de São Paulo e dos interesses cafeeiros sobre a política econômica do governo federal.

Já a atuação de Minas e da oligarquia mineira foi objeto de reflexão de Amilcar Martins Filho e Cláudia Viscardi. Martins Filho discutiu em sua tese de doutorado, defendida em 1986 na Universidade de Illinois (EUA), a natureza da economia mineira no final do século XIX e inícios do século XX e a relação entre café e política (Martins Filho, 1987). Na contracorrente da produção dominante, sublinhou o peso reduzido do café na economia do estado. Para o autor, longe de representar o interesse dos cafeicultores, o chamado estilo mineiro de fazer política deve ser visto como fruto da crise da cafeicultura, ou seja, como produto combinado, de um lado, da ausência de qualquer hegemonia econômica no estado e, de outro, da presença de uma elite política capaz de costurar divergências e usar a máquina do governo como instrumento de dominação e cooptação políticas.

Na análise do autor, é clara a perspectiva da política como uma instância dotada de capacidade própria, distinta da economia, o que relativiza modelos interpretativos, dominantes nos anos 1970, consagrados por autores como Boris Fausto, que usaram a representação de interesses, ou seja, as determinações de classe, como chave explicativa do comportamento dos atores políticos.

O trabalho de Amilcar Martins situa-se no âmbito da corrente que, diferente do modelo da representação de interesses, sustenta o caráter patrimonialista da formação histórica do Brasil, cujo principal representante é Raymundo Faoro.

Em sua obra clássica, Os donos do poder, publicada originalmente em 1957, Faoro, jurista e um dos principais cientistas sociais brasileiros, interpreta a história do Brasil reservando ao Estado um papel de destaque, e à sociedade uma face desarticulada (Faoro, 1958). Martins 
Filho, em certo sentido, trilha os passos de Simon Schwartzman em seu estudo São Pauloe o Estado nacional (Schwartzman, 1982), publicado nos anos 1980 com o título Bases do autoritarismo brasileiro, no qual faz uso do modelo patrimonialista. Segundo Schwartzman, a compreensão da experiência histórica do Brasil não deve se basear na ideia de que os detentores do poder são representantes de interesses de classes ou grupos sociais dominantes. Para o autor, os detentores do poder formam um núcleo social específico, uma espécie de classe política, composta de profissionais, cuja atuação ora garante a perpetuação de seus interesses específicos, ora é pautada pelas razões do Estado. Mas, apesar de sustentar essa perspectiva, Schwartzman concebe a existência de diferenças entre as elites regionais na Primeira Republica. Assim, defende que, se a representação de interesses melhor espelha o papel desempenhado pela elite paulista, em quase todas as outras regiões do país o patrimonialismo foi a regra.

Viscardi também contribuiu para esse debate inovando de forma significativa ao questionar a tese segundo a qual a estabilidade do regime esteve fundamentada na edição de uma aliança estabelecida entre São Paulo e Minas Gerais com base na cafeicultura. ${ }^{8}$ Anteriormente, a historiadora francesa Armelle Enders havia ressaltado, em sua análise sobre o federalismo brasileiro no período, a inexistência de uma solidez na aliança entre esses dois estados até 1920, uma vez que o Rio Grande do Sul, em algumas conjunturas importantes, apresentou-se como um parceiro preferencial para os mineiros (Enders, 1993). Viscardi mostrou, pela análise das sucessões presidenciais e acordos firmados nessas conjunturas, que a aliança entre Minas e São Paulo foi eivada de conflitos, e o pacto instituído a partir de 1898, denominado política dos governadores, não eliminou o grau de incerteza do sistema político vigente, na medida em que deixou de regular o principal elemento disfuncional do regime republicano: o fundamento de sua própria renovação. A autora não questiona a existência da aliança São Paulo-Minas Gerais, mas problematiza essa aliança e seu papel de fiador da estabilidade do regime que determinada historiografia lhe atribuiu.

Conforme defende, a estabilidade do modelo político foi garantida pela ausência de alianças monolíticas permanentes, ou seja, graças à instabilidade das alianças entre os estados mais importantes da Federação, fato que impediu, a um só tempo, que a hegemonia de uns fosse perpetuada e a exclusão de outros fosse definida.

Viscardi mostra que Minas viveu internamente árduas disputas intraelitistas, que interferiram em sua projeção nacional. Sua importância política derivou não do apaziguamento interno de suas divergências, mas de seu poder econômico de segundo estado produtor de café no ranking nacional, aliado ao fato de ter maior quociente eleitoral.

${ }^{8}$ Em seu livro, inicialmente apresentado como tese de doutorado à UFRJ, Viscardi questiona ainda a tese da existência de um consenso político mineiro interno como suporte para a projeção do estado na esfera nacional e a hegemonia exclusiva dos interesses cafeeiros no controle do Estado republicano. Esse trabalho foi publicado em 2001. 
Em 2009, Amilcar Martins publicou sua tese apresentando discordâncias em relação à contribuição de Cláudia Viscardi, embora não tenha apresentado novos dados (Martins Filho, 2009).

Uma segunda linha de trabalhos destaca as dinâmicas específicas de diferentes unidades da Federação e do Distrito Federal e suas estratégias para ampliarem seus espaços políticos no contexto de federalismo desigual por meio de tentativas de estruturação de eixos alternativos de poder. De certa forma, esses estudos vêm responder à necessidade sublinhada pelos brasilianistas, nos anos 1970, do desenvolvimento de análises priorizando o desempenho de outras unidades da Federação brasileira na Primeira República. São os casos dos estudos produzidos por Marieta de Moraes Ferrreira (1989, 1993, 1994, 2003).

Merece destaque o livro A República na velha província, que analisa a implantação do novo regime no estado do Rio e a atuação das elites políticas fluminenses entre 1889-1930. A problemática que norteia a pesquisa é a tentativa de compreensão do porquê da perda de status político e dinamismo econômico experimentado na república pela antiga província fluminense. Essas questões foram aprofundadas no trabalho Em busca da idade do ouro: as elites políticas fluminenses na Primeira República, no qual a autora defende a existência de esforços, ao longo do período, para a criação de um eixo alternativo de poder à aliança São Paulo-Minas Gerais, nos quais o estado do Rio teve papel relevante. A dificuldade de sucesso dessas iniciativas deve-se a fatores como a fragmentação das elites políticas fluminenses, as dificuldades de institucionalização da vida partidária, a forte tendência observada de personificação da política fluminense, a tendência à nacionalização, pela proximidade do Distrito Federal, e a ausência de uma efetiva integração entre os setores produtivos e o governo do estado em torno de um programa econômico que dinamizasse a economia fluminense.

A busca de um espaço de poder alternativo a Minas e São Paulo também é abordada por Vera Lúcia Borgéa Borges no livro Morte na República: os últimos anos de Pinheiro Machado e a política oligárquica (1909-1915). Seu trabalho descortina as relações políticas e a ação dessa importante liderança do estado do Rio Grande do Sul, que alcançou significativa ascendência sobre a comissão de verificação de poderes, teve participação de destaque nas eleições presidenciais de 1910, que garantiu a vitória de Hermes da Fonseca, e na política das salvações (Borges, 2004).

É igualmente importante assinalar as contribuições voltadas para a análise da dinâmica política na capital da República - a cidade do Rio de Janeiro - proporcionadas pelos trabalhos de Américo Freire (2000) e Surama Conde Sá Pinto (2002, 2011). Esses estudos revestem-se de particular importância, porque o fato de a cidade do Rio ter sediado a capital do país fez com que sua história política fosse confundida com a história política nacional. ${ }^{9}$

${ }^{9}$ Esses estudos foram construídos em um contexto marcado pelos debates ensejados pelo movimento Autonomia Carioca, identificado com a proposta da desfusão do estado do Rio com o antigo estado da Guanabara. 
Além disso, o Rio de Janeiro era, na Primeira República, um dos mais importantes centros urbanos, econômicos e financeiros do país, e o único município brasileiro com representação no Congresso (composta de 10 deputados e três senadores).

Assim, no livro Uma capital para a República, Freire analisa o longo processo de construção política da capital republicana, entre 1889 e 1906. Conforme destaca, o novo regime introduziu, a princípio, mecanismos no sistema político-institucional que vieram a fortalecer a presença das forças políticas locais no campo político carioca. ${ }^{10} \mathrm{~A}$ partir de 1897 , no entanto, o governo federal lançou mão de uma estratégia visando a exercer um maior controle sobre a dinâmica política da capital do país, que encontrou forte resistência das elites políticas cariocas. Nesse cenário, a luta pela autonomia político-administrativa se tornaria uma bandeira defendida por importantes grupos locais ao longo de todo o período.

Somando-se a esse debate, Surama Pinto testou alguns enunciados presentes no meio acadêmico, jornalístico e político que, na ausência de pesquisas empiricamente fundamentadas, acabaram se tornando "lugar-comum". São os casos das ideias da origem heterogênea dos membros das elites políticas cariocas na Primeira República, da debilidade das instituições partidárias da cidade, do Senado como órgão supervisor das instituições e/ou árbitro na política carioca, da falta de coesão da bancada carioca no Congresso, pelo fato de essas elites terem sido, em grande medida, absorvidas pelo debate político nacional, e de que o prefeito era um mero administrador ou interventor do governo federal no campo político da cidade. ${ }^{11}$ O que se evidencia em seu trabalho é que, em diferentes momentos na Primeira República, setores das elites políticas cariocas se colocaram em rota de colisão com o governo federal. Conforme se destaca, na geografia das oligarquias feita por diversos autores, se o Distrito Federal não desfrutou de uma posição privilegiada, nem por isso seu papel no conjunto da Federação brasileira deve ser subestimado.

Outras contribuições importantes no que diz respeito a estudos das demais unidades da Federação são os trabalhos de Gunter Axt (2011), José Edson de Arruda Fanaia (2010), Silvia Noronha Sarmento (2011), Antonio Luigi Negro e Jonas Brito (2013) e Leandro Quintão (2016).

O trabalho de Gunter (2011) prioriza a experiência do Rio Grande do Sul, focalizando o intervencionismo estatal na economia. O fio condutor de sua narrativa é a evolução da

\footnotetext{
${ }^{10}$ O referido modelo estabeleceu a nomeação do Executivo municipal (prefeito) pelo presidente da República, a eleição por sufrágio direto para a composição do Legislativo local e atribuiu ao Senado a prerrogativa de exame dos vetos dos prefeitos às deliberações dos legisladores municipais.

"O recorte temporal adotado pela autora compreende o período que vai de 1909 a 1922. A conjuntura engloba a Campanha Civilista e a Reação Republicana, movimentos que mobilizaram grupamentos políticos da cidade, nos quais a ideia da autonomia política do distrito emergiu nos debates. A opção não é fortuita. Segundo a autora, a política carioca tem sido estudada em conjunturas de redefinição da política nacional, e não em contextos menos conturbados, embora também marcados por certa instabilidade; daí a importância de análises em fases em que o modus faciendi da República já havia sido definido.
} 
política fiscal e orçamentária implementada pelos governos Júlio de Castilhos, Borges de Medeiros, Carlos Barbosa e Getúlio Vargas. O autor discute a posição das elites tanto governistas quanto oposicionistas no que diz respeito à política regional e diante de enfoques estratégicos da política fiscal e monetária federal.

Fanaia analisa o posicionamento de Mato Grosso no concerto republicano, tomando como referência o universo de atuação das elites e a condução de suas ações. Em seu livro, mostra as similitudes da política oligárquica mato-grossense com outras regiões do país e suas particularidades (Fanaia, 2010). No que diz respeito a esse último aspecto, destaca que o regime republicano no estado surgiu sob a égide de forte dissensão, que se prolongaria praticamente por dois terços da experiência republicana. O estudo revela que a relação entre poder central e poder local sofreu constantes deslocamentos ao longo do período, que a baixa institucionalização partidária fomentou a formação de partidos políticos personificados e núcleos familísticos de poder, que a terra assumiu papel de destaque como instrumento de barganha e obtenção de apoio político e que a tribuna do Parlamento federal foi estrategicamente utilizada para a nacionalização dos problemas estaduais.

Estudando a Bahia, Silvia Sarmento, em seu livro que priorizou o enfoque de duas lideranças que polarizaram a política estadual na Primeira República - J. J. Seabra e Rui Barbosa - demonstra o complexo quadro da política oligárquica do estado (Sarmento, 2011). A autora discute convergências e divergências entre as duas lideranças baianas, suas trajetórias na República, atuações no plano federal, de que forma dividiram a política no estado, suas propostas, estratégias de confronto e vinculações com grupos políticos, econômicos e sociais. Seu trabalho apresenta subsídios para a relativização da ideia defendida por Lessa de que houve um congelamento dos conflitos políticos, restringindo a alternância dos grupos ao poder com o pacto instituído a partir de 1898.

Na mesma linha, a análise de Luigi Negro e Jonas Brito destaca que a fragilidade da representação da Bahia, segunda maior bancada do Congresso republicano (menor apenas que a mineira, igual à dos paulistas), nos espaços centrais da disputa política, decisão e capitação de recursos no plano nacional, foi produto direto da turbulência causada pelas disputas de facções políticas estaduais, quadro que sofre alterações nos anos 1920 com a ascensão da oligarquia Calmon (Negro e Brito, 2013).

Já abordando a experiência do Espírito Santo durante a Primeira República, Leandro Quintão, em sua tese de doutorado, analisou a construção, a consolidação e a perda de poder da oligarquia de Moniz Freire no estado (Quintão, 2016). Ao recuperar a trajetória e a atuação dessa importante chefia oligarca e seu plano de afirmação regional, o autor discute as estratégias defendidas por grupos políticos capixabas para que o estado ocupasse uma melhor posição no federalismo brasileiro do período, bem como as dificuldades, oposições e obstáculos enfrentados tanto na política estadual quanto na esfera federal. 


\section{O enfoque das relações entre o público e o privado}

Outro conjunto de textos fundamental para o estudo das oligarquias na Primeira República é aquele que teve como questão principal a relação entre o público e o privado. Nos debates dessa temática, a obra pioneira e que deu contribuição significativa é Coronelismo, enxada e voto, de Victor Nunes Leal (1975). ${ }^{12}$

Publicado em 1949, o trabalho representou grande inovação no campo das ciências sociais. Estruturado com base em uma ampla e consistente pesquisa, nele há o rompimento com teses consagradas, que apresentavam a sociedade brasileira a partir de modelos dicotômicos, que opunham ordem privada a ordem pública, do qual o trabalho de Nestor Duarte (1939) é o melhor exemplo.

Preocupado em estudar o fenômeno do coronelismo, o autor discute a evolução do município brasileiro da fase colonial até a Constituição de 1946, enfocando as atribuições municipais, a eletividade de suas administrações, sua receita, sua organização policial e judiciária e sua legislação eleitoral. Partindo desse quadro geral e definindo-o como resultado da superposição de formas desenvolvidas do regime representativo a uma estrutura econômica e social inadequada (Leal, 1975, p. 20), Victor Nunes localizou o coronelismo como um fenômeno específico da Primeira República, produto de um fato político e de uma conjunta econômica. O fato político apontado como desencadeador do coronelismo foi o federalismo implantado no país pela Constituição de 1891, que concedeu ampla margem de autonomia aos estados, em detrimento dos municípios, e criou um novo ator político — os governadores, que passaram a ser eleitos a partir da máquinas estaduais. Já o fato econômico responsável pela manifestação do fenômeno foi a crise dos fazendeiros, que acarretou o enfraquecimento político do poder dos coronéis diante de seus dependentes e rivais. A manutenção desse poder passava a exigir, então, a presença do Estado, que expandia sua influência à medida que diminuía a dos donos de terras. Em uma espécie de barganha, em que a moeda era o voto, o poder público alimentava o poder local com uma autonomia extralegal, em troca do voto do eleitorado rural, que, embora incorporado ao processo político com a supressão do critério censitário, permanecia dependente social e economicamente dos proprietários rurais. Desse compromisso fundamental, que ligava chefes locais a governadores de estado e estes ao presidente da República, resultariam características secundárias do fenômeno coronelista, como o mandonismo, o filhotismo, o falseamento do voto e a desorganização dos serviços locais.

Para Victor Nunes, o coronelismo seria um momento particular do mandonismo, exatamente aquele em que os mandões começam a perder força e têm de recorrer ao governo. Longe de se tratar da mera sobrevivência do poder privado, cuja hipertrofia se constituiu em

${ }^{12}$ Desde a publicação do clássico de Nunes Leal, uma série de autores desenvolveram estudos sobre o tema. Ver: Janotti (1962), Pinto (1998) e Fortunato (2000). 
fenômeno típico da história colonial e imperial brasileiras, o coronelismo era basicamente um compromisso, uma troca de proveitos entre o poder público, progressivamente fortalecido, e a decadente influência dos chefes locais, notadamente os donos de terra. Trata-se, portanto, de uma rede complexa de relações em que os remanescentes do poder privado são alimentados pelo poder público, em função de suas necessidades eleitorais de controlar o voto do interior (predominante à época, dado o perfil da sociedade brasileira na Primeira República).

Diferentemente de Victor Nunes, Maria Isaura Pereira de Queiroz (1976) e Eul Soo Pang (1979) identificaram coronelismo com mandonismo, dilatando o uso do conceito e comprometendo sua precisão histórica ao utilizá-lo em conjunturas diversas da história brasileira. Maria Isaura atribuiu ao coronel a função de chefe de parentela, examinando-o, assim, em seu aspecto familial, relação que também seria estabelecida por Linda Lewin ao estudar diferentes famílias de coronéis paraibanos na Primeira República (Lewin, 1993). Maria Isaura também ampliou a caracterização do coronelismo para incorporar manifestações urbanas, perspectiva que não é seguida nem por Américo Freire nem por Surama Conde, que empregam o conceito de clientelismo em suas análises sobre a política da cidade do Rio de Janeiro na Primeira República (Freire, 2000; Pinto, 2011).

A primeira crítica mais contundente ao modelo interpretativo de Victor Nunes foi produzida pelo historiador inglês Paul Cammack (1979). O ponto de partida de Cammack é o questionamento da validade do conceito de compromisso coronelista. Conforme defende, o sistema político oligárquico brasileiro, na Primeira República, não deveria ser entendido a partir da noção de clientelismo (conceito por ele utilizado equivocadamente como sinônimo de coronelismo), e sim da representação de interesses das classes dominantes. Com essa proposição, Cammack defende a retomada da visão tradicional de um sistema político dominado pelos proprietários rurais cujos interesses seriam representados pelo Estado. Para o historiador inglês, Victor Nunes havia deixado de atribuir a devida importância à atuação socioeconômica dos coronéis.

A outra crítica de Cammack ao modelo de Nunes está baseada no questionamento de uma das premissas do compromisso: a da dependência do governo estadual em relação ao coronel para a produção de votos e, consequentemente, a do valor do voto como mercadoria política. Segundo Cammack, o sistema eleitoral era controlado pelo governo estadual, que não necessitava realizar nenhum acordo com o poder local, concretizado na figura do coronel.

A despeito da pertinência de alguns pontos levantados por Cammack, as linhas básicas da análise de Victor Nunes Leal permanecem atuais. Amílcar Martins Filho (1984), em seu artigo "Clientelismo e representação em Minas Gerais durante a Primeira República: uma crítica a Paul Cammack", fez uma análise das interpretações do historiador inglês, resgatando, no fundamental, a tese do compromisso coronelista. José Murilo de Carvalho, igualmente, em uma série de trabalhos, defende a validade do conceito. Apesar de reconhecer os exageros 
atribuídos ao valor do voto na Primeira República, não encara essa limitação como suficiente para invalidar o modelo de análise de Victor Nunes (Carvalho, 1984, 1997, 2011).

Outra linha de trabalho que discute as relações entre ordem privada e ordem pública está associada às interpretações, já mencionadas, de Raimundo Faoro, que, no livro Os donos do poder, analisa a formação do patronato brasileiro, vista como um processo que se inicia com a fundação do Estado português e se encerra com o governo Vargas (Faoro, 1958). A tese central é de que o Estado foi sempre onipotente no Brasil, e ao estamento burocrático coube a direção dos negócios públicos. Como o Estado é o centro de tudo, quem o personifica é a classe dirigente. No caso específico da Primeira República, com a implantação de um federalismo desvirtuado, o estamento burocrático teria sofrido declínio. Ainda assim, o poder público continuaria a atuar no sentido de solucionar crises econômicas e financeiras e, principalmente, intervir para amparar a cafeicultura.

Essa discussão tem sido renovada em teses e artigos que destacam a competição política, a questão da representação e a importância dos partidos e do voto no período, desenhando um quadro mais complexo da política na Primeira República, diferente da caricatura de um sistema político marcado por fraude, violência, clientelismo, ausência de direitos e eternização de oligarquias no poder. Como exemplos, nesse sentido podemos citar os trabalhos de Cristina Buarque de Holanda (2009), Luciano Barbosa (2013), Surama Conde Sá Pinto (1998, 2016), Vitor Fonseca (2016) e Paolo Ricci e Jaqueline Zulini (2014).

Outra abordagem do processo de construção do Estado no Brasil de 1890 a 1930 está presente no trabalho de Elisa Reis (1985). A base de seu argumento é que os interesses agroexportadores, dominantes no período, ao politizarem a economia, conferiram ao Estado uma posição estratégica que, em função de seu timing político, propiciou uma marcada autonomia do Estado diante de interesses sociais. Partindo desse ponto e retomando algumas contribuições de Victor Nunes, a autora demonstra o crescimento do Estado republicano brasileiro no período pela expansão da burocracia, do aumento de sua capacidade fiscal e do próprio aumento das forças militares.

\section{Considerações finais}

Ainda que alguns historiadores tenham chamado a atenção para certo declínio na produção de estudos sobre a Primeira República, podemos verificar uma renovação de interesse. O número especial da Revista Brasileira de História, sobre a República, o dossiê da revista Tempo - "A nova 'velha' República" - além dos livros organizados por Ângela de Castro Gomes com Alda Morão e Cláudia Viscardi com Almino Alencar, são exemplos claros nesse 
sentido. ${ }^{13}$ Isso sem mencionar o artigo de Wanderley Guilherme dos Santos, que recentemente trouxe novos subsídios para se pensar a experiência do sistema oligárquico representativo da Primeira República (Santos, 2013). De acordo com o cientista político, o sistema oligárquico brasileiro, na Primeira República, propiciou 40 anos de exemplar estabilidade institucional, sem prejuízo de ocasionais solavancos governamentais. A estabilidade governamental e legislativa foi substancialmente superior à dos 63 anos de regime imperial, em grande medida pela eficácia das regras de competição intraoligárquicas em nível nacional e do predomínio da disputa com base no voto em nível local.

Em meio à produção historiográfica analisada neste artigo, o que se pode apreender é que continua em aberto o debate sobre a natureza dos conflitos políticos e o papel do Estado no período, o que serve de estímulo para o desenvolvimento de novos trabalhos. A ideia de construção de um eixo aternativo de poder à aliança São Paulo-Minas Gerais também se mantém como algo instigante a ser aprofundado, assim como o papel dos outros estados no conjunto da Federação, bem como a natureza da aliança entre Minas e São Paulo. Também têm surgido como tema relevante as eleições e o significado do voto no contexto da Primeira República. Da mesma forma, análises das especificidades da política carioca se revelam como um importante campo de pesquisa para novos estudos. Finalmente, é fundamental a produção de trabalhos que problematizem as ideias do congelamento dos conflitos políticos e da eternização das situações estaduais no poder a partir da política dos governadores. Ficam, assim, aqui registradas nossas sugestões para novas pesquisas.

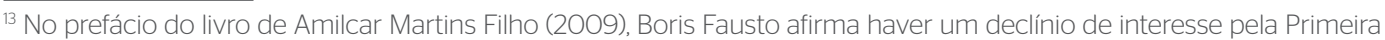
República. A renovação do interesse, no entanto, conforme afirmamos, pode ser apreendida nos números das seguintes revistas: Revista Brasileira de História (2009) e Tempo (2009), bem como nas obras dos seguintes autores: Gomes e Mourão (2012) e Viscardi e Alencar (2016). 


\section{Referências bibliográficas}

BARBOSA, Luciano Senna Peres. Viva o povo de Juiz de Fora: eleições e estratégias discursivas na Primeira República. Juiz de Fora: UFJF/Funalfa, 2013.

BASBAUM, Leôncio. História sincera da República, de 1889 a 1930. 4. ed. São Paulo: AlfaÔmega, 1976.

BEIGUELMAN, Paula. Pequenos estudos de ciência política. São Paulo: Centro Universitário, 1967. v. 1.

. Pequenos estudos de ciência política. São Paulo:

Livraria Pioneira, 1968. v. 2.

BORGES, Vera Lúcia Borgéa. Morte na República: os últimos anos de Pinheiro Machado e a Política Oligárquica (1909-1915). Rio de Janeiro: Instituto Histórico e Geográfico Brasileiro, 2004.

CAMMACK, Paul. O coronelismo e o compromisso coronelista: uma crítica. Cadernos DCP, Belo Horizonte, n. 5 , p. $120,1979$.

CANO, Wilson. Padrões diferenciados das principais regiões cafeeiras (1850-1930). Estudos Econômicos, São Paulo, v. 15, n. 2, p. 291-306, 1985.

CARDOSO, Fernando Henrique. Dos governos militares a Prudente - Campos Sales. In: FAUSTO, Boris (Org.). O Brasil republicano: história geral da civilização brasileira. São Paulo: Difel, 1975. v. 8.

CARDOSO, Vicente Licínio. À margem da história da República. Rio de Janeiro: Edição do Annuário da Brasil, 1924.

CARONE, Edgar. A Primeira República (1889-1930): texto e contexto. São Paulo: Difel, 1969.

Difel, 1971.

A República Velha: evolução política. São Paulo:

. A República Velha: instituições e classes sociais. São Paulo: Difel, 1972.

CARVALHO, José Murilo de. Coronelismo. In: BELOCH, Israel; ABREU, Alzíra Alves de (Org.). Dicionário históricobiográfico brasileiro, 1930-1983. Rio de Janeiro: Forense Universitária/Cpdoc/Finep, 1984. v. 2.

Os bestializados: o Rio de Janeiro e a República que não foi. São Paulo: Companhia das Letras, 1987.

. A formação das almas: o imaginário da República no Brasil. São Paulo, Companhia das Letras, 1990.
Mandonismo, coronelismo, clientelismo: uma discussão conceitual. Dados: Revista de Ciências Sociais, Rio de Janeiro, v. 40, n. 2, p. 229-250, 1997.

Mandonismo, coronelismo, clientelismo, república. In: BOTELHO, André; SCHWARCZ, Lilia Moritz. (Org.). Agenda brasileira: temas de uma sociedade em mudança. São Paulo: Companhia das Letras, 2011. v. 11, n. 124, p. 334-363.

DUARTE, Nestor. A ordem privada e a organização política nacional. São Paulo: Companhia Editora Nacional, 1939. Coleção Brasiliana, 172.

ENDERS, Armelle. Pouvoir et fédéralisme au Brésil: 18891930. Paris: Université de Paris IV Sorbone/Institut d'Histoire, 1993.

FANAIA, João Edson de Arruda. Elites políticas em Mato Grosso na Primeira República (1889-1930). Cuiabá: UFMT, 2010.

FAORO, Raimundo. Os donos do poder. Rio de Janeiro: Globo, 1958.

FAUSTO, Boris. A Revolução de 1930: historiografia e história. São Paulo: Brasiliense, 1970

Pequenos ensaios de história da República: 1889-1945.

São Paulo: Cebrap, 1972.

(Org.). O Brasil republicano. São Paulo: Difel, 19751981. Coleção História Geral da Civilização Brasileira, 8 e 9.

Estado e burguesia agro-exportadora na Primeira República: uma revisão historiográfica. Novos Estudos Cebrap. São Paulo, n. 27, jul. 1990.

FERREIRA, Marieta de Moraes (Coord.) A República na velha província. Rio de Janeiro: Rio Fundo, 1989.

A reação republicana e a crise política dos anos vinte. Revista Estudos Históricos, Rio de Janeiro, v. 6, n. 11, p. 9-23, 1993.

Em busca da idade do ouro: as elites políticas fluminenses na Primeira República. Rio de Janeiro: UFRJ, 1994.

Le système politique sous la Première République: un bilan des principales générations historiographiques. In: ROLLAND, Denis; SANTOS, Marie-José Ferreira dos; RODRIGUES, Simele (Org.). Le Brésil: territoire d'histoire. Historiographie de Brésil contemporain. Paris: L'Harmattan, 2013. 
; PINTO, Surama Conde Sá. A crise dos anos 1920 e a Revolução de 1930. In: FERREIRA, Jorge; DELGADO, Lucilia (Org.). O Brasil republicano. Rio de Janeiro: Civilização Brasileira, 2003. v. I.

FERREIRA, Jorge; DELGADO, Lucilia (Org.). O Brasil republicano. Rio de Janeiro: Civilização Brasileira, 2003. v. I.

FONSECA, Vitor. Voto e competição política na Primeira República: o caso de Minas Gerais. Tese (Doutorado), Universidade Federal de Juiz de Fora, Juiz de Fora, 2016.

FORTUNATO, Maria Lucinete. O coronelismo e a imagem do coronel: de símbolo a simulacro do poder local. Tese (Doutorado), Unicamp, Campinas, 2000.

FRANCO, Gustavo Barroso. Reforma monetária e instabilidade durante a transição republicana. Rio de Janeiro: BNDES, 1983.

A primeira década republicana. In: ABREU, Marcelo de Paiva (Org.). A ordem do progresso: cem anos de política econômica republicana (1889-1989). Rio de Janeiro: Campus, 1989.

FREIRE, Américo Oscar G. Uma capital para a republica: poder federal e forças políticas locais no Rio de Janeiro na virada do século XX. Rio de Janeiro: Revan, 2000.

FRITSCH, Winston. Aspectos da política econômica do Brasil: 1906-1914. In: NEUHAUS, Paulo (Org.). Economia brasileira, uma visão histórica. Rio de Janeiro: Campus, 1980a.

Pesquisa e planejamento econômico. Rio de Janeiro: Ipea, dez. 1980b. p. 713-774

Aspectos da política econômica brasileira na Primeira República. Tese (Doutorado), Universidade de Cambridge, Cambridge, 1983.

Sobre as interpretações tradicionais da lógica da política econômica na Primeira República. Estudos Econômicos, São Paulo, v. 15, n. 2, p. 339-346, 1985.

Apogeu e crise na Primeira República: 19001930. In: ABREU, Marcel de Paiva (Org.). A ordem do progresso: cem anos de política econômica republicana (1889-1989). Rio de Janeiro: Campus, 1989.

FURTADO, Celso. Formação econômica do Brasil. São Paulo: Difel, 1959.

A economia do açúcar: processo de trabalho e processo de acumulação. In: FAUSTO, Boris (Org.).
O Brasil republicano. São Paulo: Difel, 1975. v. 1. Coleção História Geral da Civilização Brasileira, 8.

GOMES, A. C.; FERREIRA, M. M. Primeira República: um balanço historiográfico. Revista Estudos Históricos, Rio de Janeiro, v. 4, 1989.

; MOURÃO, Alda (Coord.). A experiência da Primeira República no Brasil e em Portugal. Rio de Janeiro: FGV, 2012.

GUNTER, Axt. Gênese do Estado moderno no Rio Grande do Sul (1889-1929). Porto Alegre: Paiol, 2011.

HOLANDA, Cristina Buarque de. Modos de representação política: o experimento da Primeira República. Rio de Janeiro: Iuperj, 2009.

JAGUARIBE, Hélio. Desenvolvimento econômico e desenvolvimento político. Rio de Janeiro: Fundo de Cultura, 1962.

JANOTTI, Maria de Lourdes Mônaco. Os subversivos da República. São Paulo: Brasiliense, 1986a.

O coronelismo. São Paulo: Brasiliense, 1986b. Coleção Tudo é História, 13.

KUGELMAS, Eduardo. A Primeira República no período de 1891 a 1909. In: BEIGUELMAN, Paula. Pequenos estudos de ciência política. São Paulo: Pioneira, 1968. v. 2.

. Difícil hegemonia: um estudo sobre São Paulo na Primeira República. Tese (Doutorado), Universidade de São Paulo, São Paulo, 1986.

LEAL, Victor Nunes. Coronelismo, enxada e voto. São Paulo: AlfaÔmega, 1975.

LESSA, Renato. A invenção republicana. São Paulo: Vértice, 1987.

A invenção da República no Brasil: da aventura à rotina. In: CARVALHO, Maria Alice Rezende de (Org.). República no Catete. Rio de Janeiro: Museu da República, 2001.

LEVINE, Robert. A velha usina: Pernambuco na Federação brasileira. Rio de Janeiro: Paz e Terra, 1975.

LEWIN, Linda. Política e parentela na Paraíba: um estudo de caso da oligarquia de base familiar. Rio de Janeiro: Record, 1993.

LOVE, Joseph. O regionalismo gaúcho. São Paulo: Perspectiva, 1975. 
A locomotiva: São Paulo na Federação brasileira. Rio de Janeiro: Paz e Terra, 1982.

LYNCH, Cristian Edward. Da monarquia à oligarquia: história institucional e pensamento político brasileiro (1822-1930). São Paulo: Alameda, 2014.

MARTINS FILHO, Amilcar. Clientelismo e representação em Minas Gerais durante a Primeira República: uma crítica a Paul Cammack. Dados: Revista de Ciências Sociais, Rio de Janeiro, n. 27, 1984.

The white collor republic: patronage and interest representation in Minas Gerais, 1889-1930. Tese (Doutorado), Universidade de Illinois, Illinois, 1987.

. O segredo de Minas: a origem do estilo mineiro de fazer política (1889-1930). Belo Horizonte: Crisálida, 2009.

MELLO, Maria Tereza Chaves de. A República consentida. Rio de Janeiro: FGV/Universidade Federal Rural do Rio de Janeiro, 2007.

NEGRO, Antonio Luigi; BRITO, Jonas. Mãe paralítica no teatro das oligarquias? O papel da Bahia na Primeira República para além do café-com-leite. Varia Historia, v. 29, n. 51, p. 863-887, set./dez. 2013.

NEVES, Margarida de Souza. Os cenários da República: o Brasil na virada do século XX. In: FERREIRA, Jorge; DELGADO, Lucilia (Org.). O Brasil republicano. Rio de Janeiro: Civilização Brasileira, 2003. v. I, p. 13-41.

PANG, Eul Soo. Coronelismo e oligarquias. Rio de Janeiro: Civilização Brasileira, 1979.

PELÁEZ, C. M. As conseqüências econômicas da ortodoxia monetária cambial e fiscal no Brasil entre 1889-1945. Revista Brasileira de Economia, 1971.

; SUZIGAN, W. História monetária do Brasil: análise da política, comportamento e instituições monetárias. Rio de Janeiro: Ipea/Inpes, 1976. Série Monográfica, 23.

PERISSINOTTO, Renato M. Classes dominantes e hegemonia na República Velha. Campinas: Unicamp, 1994.

PINTO, Surama Conde Sá. A correspondência de Nilo Peçanha e a dinâmica política na Primeira República. Rio de Janeiro: Arquivo Público do Estado do Rio de Janeiro, 1998.

Elites políticas e o jogo de poder na cidade do Rio de Janeiro (1909-1922). Tese (Doutorado), Universidade Federal do Rio de Janeiro, Rio de Janeiro, 2002.
Só para iniciados: o jogo político na antiga capital federal. l. ed. Rio de Janeiro: Mauad X/Faperj, 2011.

A experiência político-partidária do Distrito Federal na Primeira República. In: VISCARDI, Cláudia; ALENCAR, José Almino (Org.). A República revisistada: construção e consolidação do projeto republicano brasileiro. 1. ed. Porto Alegre: PUCRS, 2016. v. 1, p. 249-286.

PRADO JR., Caio. A revolução brasileira. São Paulo: Brasiliense, 1966.

1970

História econômica do Brasil. São Paulo: Brasiliense,

QUEIROZ, Maria Isaura Pereira de. O coronelismo numa interpretação sociológica. In: FAUSTO, Boris (Org.). O Brasil republicano. São Paulo, Difel, 1976. v. 3. Coleção História Geral da Civilização Brasileira, 9.

QUINTÃO, Leandro do Carmo. Oligarquia e elites políticas no Espírito Santo: a configuração da liderança de Moniz Freire. Tese (Doutorado) Universidade Federal do Espírito Santo, 2016.

REIS, Elisa Pereira. Interesses agroexportadores e contribuição do Estado; Brasil de 1890 a 1930. In: SORJ, Bernardo; CARDOSO, Fernando Henrique (Org.). Economia emovimentos sociaisna América Latina. São Paulo: Brasiliense, 1985.

REMOND, René. Por uma história política. Rio de Janeiro: FGV, 2004.

REVISTA Brasileira de História, São Paulo, 2009, v. 29 , n. 58 .

RICCI, Paolo; ZULINI, Jacqueline. Partidos, competição política e fraude eleitoral: a tônica das eleições na Primeira República. Dados: Revista de Ciências Sociais, Rio de Janeiro, v. 57, n. 2, p. 443-479, 2014.

. Nem só à base do cacete, nem apenas compresentes: sobre como se garantiam votos na Primeira República. In: VISCARDI, Cláudia; ALENCAR, José Almino (Org.). A República revisistada: construção e consolidação do projeto republicano brasileiro. 1. ed. Porto Alegre: PUCRS, 2016. v. 1, p. 195-225.

ROMERO, Silvio. Provocações e debates: contribuições para o estudo do Brasil social. Porto: Livraria Chardron, 1910.

SANTOS, Wanderley Guilherme dos. O sistema oligárquico representativo da Primeira República. Dados: 
Revista de Ciências Sociais, Rio de Janeiro, v. 56, n. 1, p. 9-37, 2013.

SARMENTO, Silvia Noronha. A Raposa e a Águia: J. J. Seabra e Rui Barbosa na política baiana da Primeira República. Salvador: EDUFBA, 2011.

SCHWARTZMAN, Simon. São Paulo e o Estado nacional. São Paulo: Difel, 1975.

. As bases do autoritarismo brasileiro. Brasília: UnB, 1982.

SODRÉ, Nelson Werneck. Formação da sociedade brasileira. Rio de Janeiro: José Olympio, 1943. 1962.

Formação histórica do Brasil. São Paulo: Brasiliense,

SOUSA, Maria do Carmo Campello de. O processo político-partidário na Primeira República. In: MOTA, Carlos Guilherme. Brasil em perspectiva. São Paulo: Difel, 1972.

TEMPO, Niterói: UFF, v. 13, n. 26, jan./jun. 2009.
TOPIK, Steven. La revolución republicana en Brasil y la burguesia en el poder?. Siglo XIX, México, v. 3, n. 5 , p. $944,1988$.

A presença do Estado na economia política do Brasil de 1889 a 1930. Rio de Janeiro: Record, 1989.

VILELA, Anibal Villanova; SUZIGAN, Wilson. Politica do governo e crescimento da economia brasileira, 1889-1945. Rio de Janeiro: Ipea/Inpes, 1973.

VISCARDI, Cláudia Maria Ribeiro. O teatro das oligarquias: uma revisão da política do café com leite. Belo Horizonte: C/Arte, 2001.

; ALENCAR, José Almino (Org.). A República revisistada: construção e consolidação do projeto republicano brasileiro. 1. ed. Porto Alegre: PUC/RS, 2016. v. 1. WEFFORT, Francisco. Opopulismo na politica brasileira. 5. ed. Rio de Janeiro: Paz e Terra, 1978.

WIRTH, John. O fiel da balança: Minas Gerais na Federação brasileira. Rio de Janeiro: Paz e Terra, 1975. 